\title{
Filosofia na TV: indutora na formação crítica cidadã
}

\author{
Daniella Cristina Jinkings Sant'Ana' \\ Mônica Igreja do Prado²
}

\section{Resumo}

Os programas televisivos sobre Filosofia ajudam a divulgar o assunto, mesmo que o tratamento dado ao tema ainda não seja o ideal. No entanto, eles auxiliam na construção de uma visão mais crítica e reflexiva e ajudam a enfrentar os desafios éticos do mundo contemporâneo, pois fazem com que o público se interesse pelo assunto. A pesquisa exploratória ressalta, na verdade, a força da comunicação interpessoal na construção da visão de mundo, na modificação de hábitos e atitudes e na formação do sujeito (indivíduo-cidadão). Reafirma também que a televisão tem o poder de pautar assuntos e trazê-los para a agenda pública, mas que, para provocar efeitos de longo prazo, é a força de mediadores, como professores, que ajudam a formar e a moldar o ser humano. A pesquisa foi realizada dentro do Projeto de Iniciação Científica do UniCEUB, no período 2007 a 2008.

Palavras-chave: Mediação. Comunicação. Filosofia. Televisão. Professores.

\section{Introdução}

Com a chegada da Filosofia à televisão brasileira no século XXI, muitas mudanças ocorreram. Com a proposta de informar e de incitar a reflexão filosófica, surgiram alguns programas cujo conteúdo tenta fazer um paralelo entre a Filosofia e o cotidiano. Os mais

1 Daniella Cristina Jinkings Sant'Ana é bacharel em Jornalismo pelo Centro Universitário de Brasília (UniCEUB) e aluna do curso de Filosofia da Universidade de Brasília (UnB). Foi bolsista do Programa de Iniciação Científica do UniCEUB no período 2007 a 2008. Contato: djinkings@gmail.com.

${ }^{2}$ Mônica Prado é jornalista, mestre em Comunicação pela Universidade de Brasília em 2001 e, atualmente é docente do Centro Universitário de Brasília (UniCEUB) no curso de Comunicação Social, e docente do Instituto de Educação Superior de Brasília (IESB), no curso de Pós-Graduação de Assessoria em Comunicação Pública. Integra o grupo de pesquisa Educação Superior e Comunicação, registrado no Diretório de Grupos de Pesquisa do CNPq. Atuou em diversas empresas jornalísticas e de comunicação. Contato: pradomonica2004@yahoo.com.br. 
conhecidos são os programas Café Filosófico, da TV Cultura; Ética, do canal Futura; o quadro Ser ou Não Ser?, do Fantástico (reapresentado recentemente no canal GNT); além disso, há a presença da filósofa Márcia Tíburi no programa Saia Justa, também do canal GNT. De acordo com os editores do quadro Ser ou Não Ser, Eugênia Moreyra e Bruno Bernardes, os programas não pretendem ensinar Filosofia academicamente, mas oferecer ao telespectador uma iniciação ao tema e a possibilidade de refletir a respeito dele.

Porém, o que duas áreas tão antagonicamente estereotipadas, nos dias atuais, - Filosofia é um exercício de reflexão, apenas afeto a doutos da academia; a televisão, o símbolo do entretenimento, do vazio crítico e do valor da aparência - estão fazendo juntas? Ora, ajudando a impulsionar a resolução de problemas que desafiam a sobrevivência da espécie humana, uma vez que o pensar crítico e racional é importante para que as respostas sejam achadas.

A pesquisa buscou analisar a convergência entre a Filosofia e a mídia (mais especificamente, a televisão e os efeitos gerados pelo consumo dos programas de Filosofia), pois o indivíduo se vê afetado por esses produtos e reage a eles de maneiras diferentes. $\mathrm{O}$ consumidor de produtos midiáticos é, acima de tudo, um sujeito ativo, ou seja, ele interpreta o que recebe, rejeita o que não agrada e absorve o que interessa. A pesquisa sobre Filosofia na TV tomou como premissa o consumidor ativo. Essa é a tendência dos estudos teóricos sobre os efeitos dos meios de comunicação (estudos de recepção e audiência) nos dias de hoje.

Assim, a pesquisa Filosofia na TV - indutora na formação crítica cidadã teve como objetivo analisar a mediação que professores de Filosofia realizam em salas de aula a partir dos conteúdos veiculados pela televisão. A pesquisa também buscou evidências dos efeitos dessa mediação em alunos e em consumidores de conteúdos filosóficos. O objetivo geral foi investigar traços de que a presença da Filosofia na TV e a mediação de professores na esfera midiática contribuem para uma formação mais crítica do indivíduo-cidadão.

O quadro investigativo visou dar suporte à hipótese de que o estudo filosófico por meio da televisão contribui na formação crítica cidadã. Ao apropriar-se de um conteúdo e vivenciar a sua mediação, o efeito, no médio e longo prazos, tende a ser a formação de um indivíduo filosoficamente mais comprometido consigo mesmo e com o mundo em que está inserido. 


\section{Filosofia na TV, é possível?}

A busca pela sabedoria foi um dos fatores que impulsionaram o desenvolvimento da sociedade. Além de estar presente na história da humanidade, a Filosofia sempre constituiu um dos pilares da construção do pensamento humano. No entanto, há pessoas que acreditam que essa área de conhecimento é inacessível aos não intelectuais, pois vêem a Filosofia como algo maçante e difícil. De acordo com a filósofa Marilena Chauí (2008, p. 25), na obra Convite à Filosofia, atualmente, costuma-se chamar de "filósofo" a pessoa distraída, com a cabeça no "mundo da lua”, pensando e dizendo o que ninguém entende.

Além disso, o progresso da tecnologia contribuiu para a falta de interesse na reflexão filosófica. Nunca o mundo contemporâneo se viu tão influenciado pelos meios de comunicação, em especial a televisão e as novas mídias, como a Internet, que trouxeram uma nova proposta aos consumidores de produtos midiáticos: a de ter a informação de forma rápida e precisa, como produto de consumo, sem a necessidade de reflexão.

Por isso, a intersecção Filosofia - Televisão veio contribuir para a possibilidade de promover experiências que sejam indutoras na formação crítica do indivíduo. O teólogo e filósofo brasileiro José Trasferetti, em seu livro Filosofia, Ética e Mídia, aborda esse entroncamento:

Para construir a cidadania, tendo como interlocutor privilegiado os meios de comunicação social, é preciso uma atitude filosófica que supere o imediatismo e o pragmatismo inerente ao individualismo reinante em nossa sociedade. Os meios de comunicação estão incorporados à nossa realidade cotidiana, fazem parte do nosso dia a dia. Não se trata de superá-los, ou de evitá-los, mas de entrar em comunhão com seu real significado e transformá-lo num instrumento de razão científica (TRASFERETTI, 2001, p. 186).

Além disso, o psicólogo norte-americano John Condry (1999, p. 38) afirmou que a televisão influencia os telespectadores

A influência exercida pela televisão baseia-se em dois fatores: o tempo passado a vê-la e o conteúdo dos programas. Quanto mais tempo o telespectador passa diante da televisão, mais sofre sua influência, ainda que esta dependa, em certa medida, do conteúdo. 
Embora a televisão, às vezes, influencie negativamente, ela possibilita algo que anteriormente era impossível, a interação com outras culturas e realidades. Por isso, o pedagogo Joan Ferrés (1996, p. 60) acredita que ela possibilita o conhecimento dos problemas de outros povos, grupos ou pessoas, além de gerar forte sentimento de participação, pois envolve cada indivíduo nos acontecimentos da humanidade. "Enfim, a televisão é uma poderosa arma de conscientização e sensibilização".

A televisão também pode pautar os assuntos discutidos pela sociedade; $\mathrm{o}$ termo mais conhecido para essa ação é agenda-setting. Segundo o professor de Comunicação Luiz Martins da Silva (2005, p. 44), "as pessoas tendem a incluir ou excluir da sua pauta de assuntos os temas que os mass media incluem ou excluem da sua seleção de conteúdos. Os mass media são muito eficazes em indicar sobre o que pensar".

O ponto chave dos estudos contemporâneos sobre esses efeitos é a forte presença da comunicação interpessoal como mediadora e interface para a construção de opiniões, saberes, valores, atitudes, crenças e comportamentos, assim como de instituições mediadoras de construção de significado.

A comunicação interpessoal é, portanto, a base da construção de sentidos porque ela se realiza no contexto dinâmico e diário da vida de cada indivíduo e na presença de um emissor e de um receptor. No âmbito da Teoria da Mediação, "a construção de significados dependeria de quem interpreta os conteúdos e do contexto de recepção dos conteúdos" (SOUZA, 2002, p.126).

Os efeitos midiáticos foram sistematizados pela Teoria da Dependência. Segundo essa abordagem teórica, há efeitos cognitivos, afetivos e comportamentais. Além disso, os estudos contemporâneos preocupam-se com o tipo de influência dos meios (direta, indireta, social e individualmente) e com o tempo em que os efeitos começam a aparecer (em curto, médio e longo prazos).

Nesse contexto, é corrente, na América Latina e em estudos brasileiros sobre recepção, a questão das mediações. Instituições como escola, família, Igreja e grupos sociais são mediadoras das informações dos meios. Pesquisa de Denise Accioly com educadoras no Rio Grande do Norte aponta que é preciso assistir aos programas de televisão para fazer ligação com os conteúdos de aprendizagem, pois 
a programação televisiva influencia o comportamento, as conversas, os códigos, os valores e os saberes dos alunos.

Constatamos que as educadoras reconhecem a presença e a influência da televisão na vida dos educandos, mas nem sempre vêem na instituição escolar uma aliada capaz de auxiliar na reflexão crítica da mídia, delegando responsabilidade maior para a família (ACCIOLY, 2006, p.13).

Accioly conclui que a representação que as educadoras têm da televisão contribui para reflexão e análise sobre a mídia na formação docente, uma vez que essa representação se reflete na prática profissional e no diálogo da mídia dentro do espaço escolar. Ou seja, a mediação dos professores em relação aos alunos está condicionada à mediação que outros sujeitos fizeram em relação aos professores.

\section{Metodologia}

A metodologia teve como base a pesquisa exploratória, qualitativa, amostragem por conveniência, entrevistas em profundidade e questionários semiestruturados. O caminho para a pesquisa acadêmica sobre Filosofia na TV consistiu em três grandes etapas. A partir da aplicação de questionários estruturados, os sujeitos deste trabalho foram professores de ambos os sexos e de diferentes faixas etárias que, efetivamente, ministram aulas de Filosofia nos Ensinos Médio e Superior; alunos de ambos os sexos e de diferentes faixas etárias que, voluntariamente, aceitaram participar da pesquisa acadêmica; pessoas que têm interesse no assunto (não graduados em Filosofia que frequentam cursos especializados por conta própria) e pessoas que não têm contato algum com a área.

A primeira etapa foi composta pelo levantamento exploratório, por intermédio de pesquisas na Internet, em sítios e "blogs" que abordaram a chegada da Filosofia à TV e os programas correspondentes a esse tema.

A segunda etapa foi composta pela elaboração, aplicação e análise das entrevistas com professores de Filosofia do Distrito Federal. O cerne das entrevistas com os docentes foi a mediação dos conteúdos dos programas de Filosofia veiculados pelas emissoras de televisão. 
A terceira etapa teve como alvo grupos de alunos, grupos de interessados em Filosofia e pessoas que não tinham contato direto com a área, mas que, voluntariamente, aceitaram participar da pesquisa acadêmica. Os voluntários responderam às entrevistas semiestruturadas aplicadas a cada um dos grupos.

Onze questionários foram respondidos por pessoas que se relacionavam com Filosofia por meio de cursos especializados, tinham idade entre 25 e 35 anos e formação que do Ensino Fundamental à Pós-graduação.

As pessoas que não tinham nenhum contato direto com a Filosofia, como cursos ou aulas, foram incluídas no Projeto após a apresentação parcial da pesquisa. Dezoito questionários foram respondidos por essas pessoas. Nove respondentes estavam na faixa entre 20 e 30 anos; sete, entre 30 e 40 anos e apenas dois com mais de 40 anos. A formação ia do Ensino Fundamental à Pós-graduação. É importante salientar que os dados desse grupo foram cruzados pelo nível de escolaridade dos respondentes.

Apenas seis questionários foram respondidos por estudantes de Filosofia de Ensino Superior. Quatro foram estudantes de universidade pública e dois de faculdade particular; a média de idade era de 23 anos.

Ao todo, quatro professores responderam ao questionário de 31 perguntas, entre fechadas e abertas. O questionário aplicado seguiu, em linhas gerais, o modelo CAP (Conhecimento, Atitudes e Práticas). Os quatro professores respondentes lecionam há mais de cinco anos, são graduados em Filosofia, sendo que três são pós-graduados. Dois lecionavam em escola privada de nível superior e dois em escola pública de nível médio.

Dois instrumentos foram basicamente utilizados para a pesquisa. O primeiro foi um roteiro de entrevista elaborado no decorrer do Projeto com o objetivo de conhecer qualitativamente as relações de mediação feitas pelos professores de Filosofia e os programas exibidos na televisão brasileira, mais precisamente na TV Cultura e pelas Organizações Globo, no canal aberto - TV Globo (Programa Fantástico) e nos canais por assinatura (Futura e GNT). O segundo foi o questionário semiestruturado para a entrevista. Durante dois meses, foram respondidos trinta e nove questionários, cujos resultados contribuíram para compreender que os programas sobre Filosofia são relevantes e ajudam a complementar o conhecimento sobre o assunto. 


\section{Resultados}

Os programas televisivos sobre Filosofia são importantes, pois ajudam a divulgá-la. No entanto, ainda que tratem os assuntos de modo superficial, auxiliam na construção de uma visão mais crítica, reflexiva e no enfrentamento dos desafios éticos do mundo contemporâneo, funcionando como um "despertar" para o assunto.

É importante salientar que a televisão, por sua especificidade como veículo de comunicação, tem dificuldade em aprofundar assuntos. Também vale ressaltar o valor dos professores e das instituições escolares como mediadores para o contato com a Filosofia, como apontado pelos respondentes da pesquisa, os quais também disseram que o desafio é incorporá-la ao dia a dia.

Para pessoas comuns que não têm relação direta com a Filosofia, essa área de conhecimento está presente no mundo contemporâneo, pois os temas filosóficos além de estarem interligados às profissões e ao dia a dia das pessoas, também ajudam a lidar com as situações da vida. Para eles, independentemente do nível de escolaridade, a Filosofia deveria ser mais divulgada e estudada em escolas de todo o país, inclusive em oficinas e cursos livres, uma vez que ajudam a compreender o ser e o mundo, a pensar criticamente a realidade e o mundo em que se vive e a usar o raciocínio de maneira mais clara e objetiva.

Os estudantes de Filosofia e as pessoas que se relacionam com essa área de conhecimento entendem que os programas de televisão, apesar de superficiais, podem estimular a obtenção de postura mais ética diante do mundo. Os professores constituem, assim, a força mediadora para a construção de um pensar mais crítico para a formação da cidadania, cuja importância é ressaltada também pelo grupo de estudantes e de pessoas que se relacionam com a área.

É importante ressaltar que a qualidade da mediação cresce à medida que os professores entram em contato com os produtos midiáticos sobre Filosofia veiculados em canais abertos e fechados.

Os docentes que constantemente estão em contato com os produtos midiáticos são os que mais refletem sobre os programas, conversam e emitem suas opiniões, seja no grupo familiar, entre seus pares no ambiente de trabalho, seja dentro de sala de aula, incorporando formalmente a programação televisiva sobre Filosofia 
em seus planos didático-pedagógicos. Os professores entrevistados perceberam mudanças no comportamento dos alunos depois das aulas de Filosofia, nas quais os assuntos foram contextualizados e integrados à experiência de vida dos estudantes. Segundo eles, os alunos ficaram compenetrados, passaram a se expressar melhor e a prestar mais atenção às aulas. A dinâmica de consumo de programas televisivos sobre Filosofia entre alunos e professores permite ao docente exercer a função de contextualização e, assim, realmente dialogar com os alunos, o que leva a uma formação mais crítica sobre o mundo em ambos os sujeitos.

Já os estudantes de Filosofia reclamaram da falta de uso de recursos em sala de aula, como filmes e programas sobre Filosofia, para dinamizar o espaço acadêmico. A reclamação procede, pois os professores que usam esses recursos afirmam que eles imprimem dinâmica às aulas. No entanto, a pesquisa apontou que o uso de programas de televisão em sala de aula não é unânime entre os docentes, pois há quem acredite nos programas como uma forma de complementar a educação dos alunos e há quem resista a essa nova experiência.

\section{Considerações finais}

A pesquisa demonstrou que, apesar da superficialidade de alguns programas, os programas televisivos sobre Filosofia constituem atualmente uma inovação que ainda tem muito a oferecer no âmbito da reflexão e da crítica, tão importantes para os indivíduos.

De acordo com o autor da obra Filosofia e Sociedade da Informação JeanClaude Chirollet, a televisão desempenha um papel educativo, mas a Filosofia ainda é representada de forma forçada ou caricaturada. Além disso, ele acredita que o discurso filosófico deve se ajustar às exigências da mediação:

[...] natureza mais ou menos justificada das questões, tempo de palavras limitado, necessidade de abreviar, de simplificar, e até de caricaturar as respostas, pressão psicológica ligada ao dispositivo audiovisual, artificialismo dos exemplos ilustrativos e mesmo de alguns dos temas da emissão, sem falar da falta de coerência das intervenções, na qual muitas vezes se perde a questão colocada à partida, ou então que se queira retomá-la artificialmente a todo custo, nem que seja para mostrar certa aparência intelectual aos telespectadores (CHIROLLET, 2000, p. 11). 
A pesquisa exploratória Filosofia na TV: indutora na formação crítica cidadã realizada no período 2007/2008 como Programa de Iniciação Científica - PIC UniCEUB, além de ressaltar a força da comunicação interpessoal na construção da visão de mundo, na modificação de hábitos e atitudes e na formação do sujeito (indivíduo-cidadão), contribui para entender que a televisão tem o poder de agendar assuntos e fazer o público interagir com eles, porém não é ela, como meio de comunicação de massa, nem o conteúdo de sua programação que causam impacto direto no indivíduo, mas a força de mediadores, como os professores que, em sala de aula, ajudam a formar o senso crítico dos indivíduos.

A convergência - Filosofia e Televisão - é ainda pouco explorada no âmbito dos estudos acadêmicos. O sentido exploratório e inusitado engrandece a pesquisa realizada e contribui para o avanço dos estudos sobre mediação e efeitos em longo prazo, dentro do campo de estudo da Comunicação Social.

Diante dos dados coletados em quatro populações distintas (professores de nível superior e de nível médio; alunos de Filosofia; pessoas que têm interesse no assunto, mas não são graduadas em Filosofia e pessoas que não têm nenhum contato com a área) e diante dos resultados alcançados, é possível afirmar que a pesquisa apontou evidências de que a presença de programas de Filosofia na televisão, aliada à recente obrigatoriedade do ensino de Filosofia e Sociologia nas escolas de Ensino Médio e, respaldada pela mediação de professores dentro de sala de aula, contribui para a formação mais crítica do indíviduo-cidadão, filosoficamente mais comprometido não só consigo mesmo, mas também com a coletividade.

\section{Philosophy on TV: inducing the citizens' critical formation}

\section{Abstract}

The TV programs about Philosophy are interesting, they help to make philosophy a public topic, but they do not get to the core of it, as they still talk about it in a superficial manner. Even like that they still help to develop a critical and reflexive view of the world and to fight the ethical challenges of the contemporary society, working as an awakening factor to the topic. The research points out the strength of the interpersonal communication in modifying habits and attitudes 
for the formation of the citizenship. Also re-states that television has the power to book some topics and to bring others to the public agenda. However, the real effect is actually caused by the strength of the mediators, as teachers, which help to form and give shape to a human being in the social environment and in the classroom. The research was developed within Programa de Iniciação Científica (PIC) from UniCEUB, between 2007/2008.

Keywords: Mediation. Communication. Philosophy. Television. Teachers.

\section{Referências}

ACCIOLY, Denise Cortez da Silva. As relações entre a escola, a família e a televisão: contribuições para a formação do telespectador. In: CONGRESSO BRASILEIRO DE CIÊNCIAS DA COMUNICAÇÃO, 29., Brasília, 2006. Anais... Brasília: Universidade de Brasília.

BACCEGA, Maria Aparecida. Televisão e educação: a escola e o livro. Revista Comunicação \& Educação, São Paulo, n. 24, p. 7-14, maio/ago. 2002.

CHAUÍ, Marilena. Convite à filosofia. 13. ed. São Paulo: Ática, 2008.

CHIROLLET, Jean-Claude. Filosofia e sociedade de informação. Lisboa: Instituto Piaget, 2000.

FERRÉS, Joan. Televisão e educação. Porto Alegre: Artes Médicas, 1996.

MACHADO, Arlindo. A televisão levada a sério. São Paulo: Senac, 2000.

POPPER, Karl; CONDRY, John. Televisão: um perigo para a democracia. Lisboa: Gradativa, 1995.

SILVA, Luiz Martins da. Teorias da comunicação no século XX. 3. ed. Brasília: Casa das Musas, 2005.

SOUZA, Jorge Pedro. Teorias da notícia e do jornalismo. Chapecó: Argos, 2002.

TRASFERETTI, José Antonio (Org.). Filosofia, ética e mídia. São Paulo: Alínea, 2001. 